\title{
Conexões entre pescadores e polvos na comunidade de Coroa Vermelha, Santa Cruz Cabrália, Bahia
}

\author{
Viviane S. Martins ${ }^{1 *}$, Francisco José Bezerra Souto ${ }^{2} \&$ Alexandre Schiavetti ${ }^{3}$
}

${ }^{1}$ Programa de Doutorado em Ambiente e Sociedade, Núcleo de Estudos e Pesquisas Ambientais, Universidade Estadual de Campinas, Rua dos Flamboyants, 155, Cidade Universitária Zeferino Vaz, 13083-867, Campinas, São Paulo, Brasil.

${ }^{2}$ Laboratório de Etnobiologia e Etnoecologia, Departamento de Ciências Biológicas, Universidade Estadual de Feira de Santana, Av. Transnordestina, s.n., Novo Horizonte, 44036-900, Feira de Santana, Bahia, Brasil.

${ }^{3}$ Universidade Estadual de Santa Cruz, Campus Soane Nazaré de Andrade, Km 16, Rodovia Ilhéus-Itabuna, 45650-000, Ilhéus, Bahia, Brasil.

\begin{abstract}
Resumo - Os recifes de corais estão entre os ecossistemas mais diversos do mundo e, além de desempenharem funções ecológicas importantes, possuem relevante papel socioeconômico por serem fonte de renda e subsistência de diversas comunidades. O distrito de Coroa Vermelha, situado no município de Santa Cruz Cabrália, estado da Bahia, compõe, juntamente com a parte norte do município de Porto Seguro, a APA Coroa Vermelha. A pesca artesanal de polvo (Octopus spp.) tem grande importância para a sobrevivência de boa parte da população local, ainda que o turismo seja uma alternativa cada vez mais promissora. Neste estudo, é abordado o comportamento de pescadores de polvo de Coroa Vermelha com relação ao recurso explotado e demais elementos do ecossistema, bem como suas possíveis implicações conservacionistas segundo a proposta etnoecológica abrangente. Inicialmente foram realizadas entrevistas não-estruturadas e, posteriormente, semiestruturadas e estruturadas, com pescadores de polvo encontrados casualmente e com os "especialistas nativos". As entrevistas semiestruturadas foram gravadas e transcritas de forma verbatim. Foi empregada também a técnica de observação direta, onde informantes foram acompanhados durante a pesca. Vinte pescadores foram entrevistados; dentre os quais, oito foram considerados "especialistas nativos". Duas técnicas de captura foram registradas, o polvejamento por cima do recife e através de mergulho, e cinco sítios de coleta foram citados como os mais frequentemente explotados pelos polvejadores locais. Dentre as conexões propostas, a ser humano/vegetal foi a mais fraca e a ser humano/ animal a mais forte na pesca de polvo.
\end{abstract}

Palavras-chave adicionais: etnoecologia, pesca artesanal.

\begin{abstract}
Connections between fishermen and octopus in Coroa Vermelha Community, Santa Cruz Cabrália, Bahia, Brazil) - Coral reefs are one of the most diverse ecosystems in the world and apart from carrying out important ecological functions, they have an important socioeconomic role because they are source of income and livelihoods for several communities. Coroa Vermelha, is a district of Santa Cruz Cabrália, State of Bahia, and, together with the northern portion of Porto Seguro, it comprises the Coroa Vermelha APA (Environmental Protection Area). The artisanal fishing of octopus still plays an important role for the local population, although tourism is a more promising alternative. This study covers the behaviour of the octopus fishermen from Coroa Vermelha relating to their catch, other elements of the ecosystem, and possible conservation implications, following a broad ethnoecological approach. Non-structured interviews, followed by semi-structured and structured interviews, with randomly selected octopus fishermen and with "native specialists", were carried out. The semi-structured interviews were recorded and transcribed verbatim. The technique of direct observation, when fishermen were accompanied during the fishing, was also used. Twenty fishermen were interviewed; eight of whom were considered "native specialists". Two techniques of capture were reported, the catching of octopus over the reef and through diving, and five sampling points were cited as the most frequently fished by the local octopus fishermen. Amongst the proposed interactions, that of human/plant interactions was found to be the weakest and that of human/animal the strongest when fishing for octopus.
\end{abstract}

Additional key words: ethnoecology, artisanal fishing.

Os recifes de corais são ecossistemas marinhos encontrados em águas quentes e claras e estão entre os mais produtivos do mundo. Apesar de ocuparem uma pequena área dos oceanos (cerca de $0,2 \%$ ), abrigam aproximadamente $25 \%$ das espécies marinhas em pelo menos uma etapa do seu ciclo de vida (Kikuchi et al. 2003). As comunidades coralíneas brasileiras são compostas por

\footnotetext{
*Autora para correspondência: martins.viviane@gmail.com

Editor responsável: Rômulo Romeu Nobrega Alves

Recebido: 16 maio 2011; aceito: 8 set. 2011.
}

poucas espécies de corais, estando os recifes distribuídos descontinuamente em estreitas faixas nas proximidades da costa. Estas faixas formam um sistema ecológico diversificado em termos de história, morfologia e biota (Castro 1997). No Brasil, os recifes de corais apresentam alta taxa de endemismo (Gomes et al. 2001) e estão distribuídos em trechos da costa nordeste, sendo essas as únicas formações desse tipo no Atlântico Sul (Amaral \& Jablonski 2005).

Além de funções ecológicas fundamentais, esses 
ecossistemas também possuem importante papel socioeconômico, seja devido ao fornecimento de recursos pesqueiros que sustentam diversas comunidades, seja pelo potencial turístico que representam. No extremo sul do estado da Bahia, tem-se um bom exemplo desta forte relação entre comunidades tradicionais e recifes de corais. Coroa Vermelha é uma comunidade onde as atividades pesqueiras ainda são essenciais para a sobrevivência de grande parte da população. Embora o turismo seja uma alternativa cada vez mais promissora, a subsistência está fortemente associada à pesca. A captura de polvos está, juntamente com a pesca de camarão, lagosta e peixe, entre as atividades pesqueiras de maior destaque em Coroa Vermelha (Martins et al. 2011).

A etnoecologia tem se mostrado uma importante ferramenta teórico-metodológica em estudos envolvendo ecologia e culturas (Souto \& Marques 2006). Segundo a proposta etnoecológica abrangente (Marques 2001, p. 16), a etnoecologia é "o campo de pesquisa (científica) transdisciplinar que estuda os pensamentos (conhecimentos e crenças), sentimentos e comportamentos que intermediam as interações entre populações humanas e os demais elementos do ecossistema que as incluem, bem como dos impactos ambientais daí decorrentes".

Dentro do enfoque teórico-metodológico da etnoecologia, a pesca artesanal no Nordeste do Brasil tem despertado interesse em um número crescente de pesquisadores desde o início da década de 1990 (e.g., Marques 1991; Nishida 2000; Montenegro 2002; Mourão 2002; Thé 2003; Souto 2004; Mourão \& Nordi 2006). Enquanto estudos sobre a pesca comercial de polvos no
Brasil têm sido desenvolvidos sobretudo no Sudeste (e.g., Tomás 2003), a pesca artesanal do polvo só começou a ser estudada mais recentemente (Leite 2007), sendo escassas as pesquisas etnoecológicas sobre o assunto (Martins 2008; Martins et al. 2011). Dessa maneira, este estudo buscou descrever as conexões entre pescadores e polvos em Coroa Vermelha e suas possíveis implicações conservacionistas.

\section{MÉTODOS}

As interações entre pescadores e polvos na comunidade de Coroa Vermelha foram estudadas segundo a abordagem etnoecológica abrangente (Marques 1995). As atividades de campo foram iniciadas em julho de 2006 e se estenderam até abril de 2008, em sete incursões a campo, cada uma com duração média de uma semana (totalizando aproximadamente 49 dias de campo) no distrito de Coroa Vermelha, Santa Cruz Cabrália, Bahia (Figura 1).

Inicialmente foram realizadas entrevistas informais (não estruturadas) com a finalidade de apreender o linguajar nativo, compreender a dinâmica da comunidade de modo geral e assim iniciar o rapport (relação de confiança mútua entre pesquisador e sujeito da pesquisa). Em seguida, foram realizadas 20 entrevistas semiestruturadas, seguindo um roteiro de perguntas pré-estabelecido sobre a atividade de captura do polvo, relações comerciais e técnicas de captura. Os entrevistados foram contatados a partir de indicação de outro(s) pescador(es) ou seguindo o critério de “especialistas nativos" (Marques 1995), que são pessoas com competência cultural na atividade, reconhecidas por

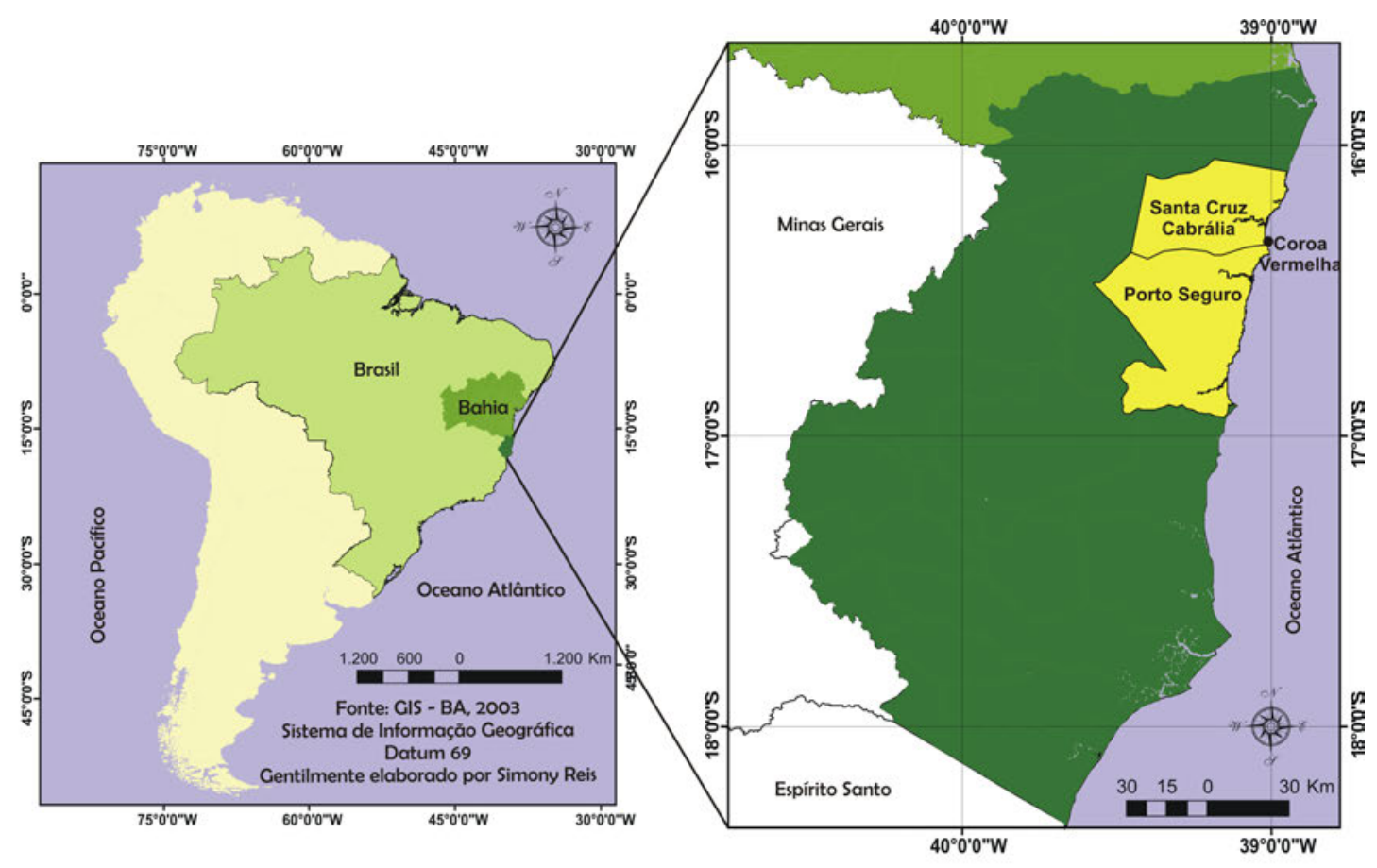

Figura 1. Localização do distrito de Coroa Vermelha, Santa Cruz Cabrália, Bahia. 
elas mesmas e pela comunidade. Seguindo a orientação do Comitê de Ética em Pesquisa (CEP-UESC), as entrevistas foram sempre precedidas da leitura do Termo de Consentimento Livre e Esclarecido. Ao final de cada entrevista semiestruturada, solicitava-se a cada entrevistado que indicasse outros pescadores de polvo para que fossem também contatados, seguindo a técnica "bola-de-neve" (Bailey apud Silvano 2001). O número de entrevistados foi considerado satisfatório quando os pescadores indicavam outros que já haviam sido contatados, não havendo maneira de se ampliar a amostragem.

Os resultados foram expressos através da caracterização das cinco Conexões Básicas (ser humano/ mineral, ser humano/vegetal, ser humano/animal, ser humano/ser humano e ser humano/sobrenatural), seguindo a proposta da Etnoecologia Abrangente (Marques 1995).

\section{Resultados E Discussão}

A "pesca de polvo" em Coroa Vermelha é também denominada "polvejamento", e seus executores são conhecidos localmente como "polvejadores". O fato de haver uma denominação específica para as pessoas que se dedicam a esta atividade pode ser um indício de que a identidade está fortemente associada ao recurso do qual ela depende e dá uma ideia do quão importante do ponto de vista cultural é a relação entre seres humanos e polvos na localidade.

\section{Conexão Ser Humano / Mineral}

$\mathrm{O}$ instrumento utilizado para a realização do polvejamento é denominado "bicheiro". Essa ferramenta
(Figura 2) consiste em um gancho feito com um pedaço de ferro (com uma volta na extremidade) que é utilizado para fisgar e remover o animal do abrigo. O objeto é confeccionado, geralmente, pelos próprios pescadores a partir de vergalhões de ferro oriundos de construção civil. O mesmo instrumento foi registrado na captura de polvos na Vila de Garapuá, estado da Bahia (Jambeiro 2002) e no arquipélago de Fernando de Noronha (Leite 2007), e ainda na catação do bivalve unha-de-velho no litoral paraibano (Nishida 2000). Neste caso, o bicheiro (de origem mineral) é utilizado como meio para conectar o pescador ao recurso polvo.

Em Coroa Vermelha, o bicheiro é empregado na remoção do polvo do seu abrigo ("loca") tanto no polvejamento sobre o platô recifal, quanto no subaquático:

"O polvo tem duas forma de pescar.. cê vai com o bicheiro né? Por cima da pedra com dois bicheiro... da mesma forma é feito pescando ele no de mergulho, de bicheiro."

A conexão com o mineral ocorre também no transporte dos polvos capturados durante a pesca. Na localidade, utiliza-se a "enfieira", que é um fio de cobre oriundo de instalações elétricas. Nesse caso, os polvos capturados são perfurados e amarrados pelo fio e nele são transportados não apenas sobre o recife, durante a pescaria, como também no trajeto até a residência do pescador. Algumas vezes o próprio bicheiro pode ser utilizado como enfieira.

O transporte de polvos em enfieiras foi muito pouco observado no polvejamento local, e um caso de mudança de uma conexão para outra (shift) foi relatado por um polvejador que afirmou ter deixado de utilizá-la como meio

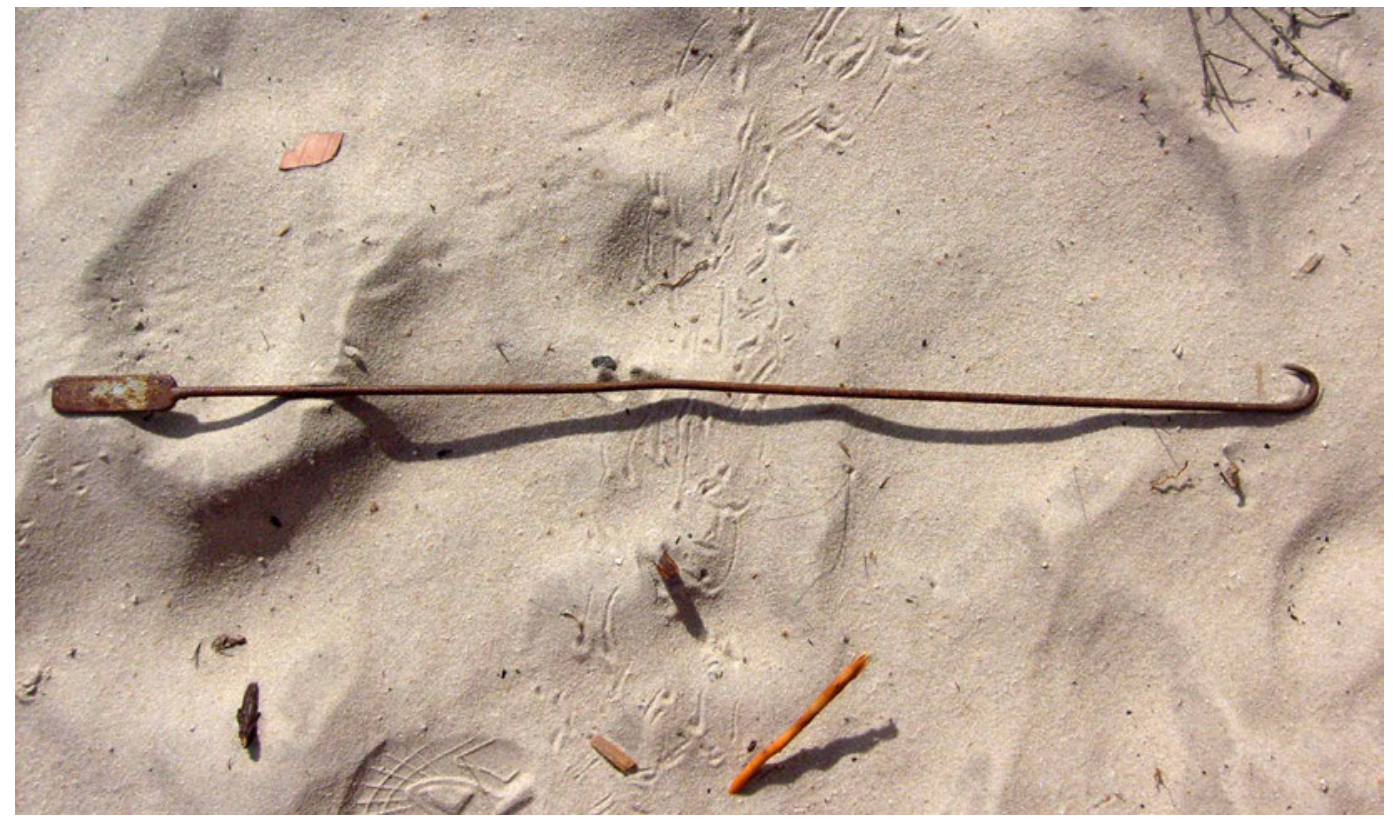

Figura 2. Bicheiro - instrumento empregado na captura de polvos em Coroa Vermelha, Santa Cruz Cabrália, Bahia. 
de transporte dos polvos e passou a utilizar o saco plástico na tentativa de estabelecer um segredo de pesca.

"Eu por exemplo, antigamente, eu trazia meu polvo na enfieira né? Hoje, como cresceu o número de pescadores eu já trago mais ele dentro da sacolinha, né? Aí a pedra é miudinha, entendeu? Aí se você ver eu com uma corda de polvo de cinco quilo, aí no outro dia tem cinco, seis, rodando na sua frente lá, rodando assim. Então não é nem negócio de usura, né? É segredo mesmo. O que os olhos não vêem, o coração não sente."

Os recursos minerais utilizados no polvejamento não são encontrados no ambiente, mas ainda assim, são fundamentais para conectar pescadores e polvos. Souto (2004) também considerou material alóctone (os paralelepípedos) utilizados em rede e groseira dentro da conexão mineral. Na pesca de polvo, o mineral é de suma importância porque para se chegar à conexão-fim (ser humano/polvo) é necessário que ocorra a conexão intermediária (ser humano/mineral). Esta conexão, portanto, pode ser considerada forte porque uma vez desfeita, provavelmente descaracterizaria a pesca de polvos da maneira como é realizada na localidade.

\section{Conexão Ser Humano / Vegetal}

A única utilização vegetal observada no polvejamento foi o cabo de alguns bicheiros que são feitos de madeira (Figura 3). Nem todos os bicheiros possuem essa configuração, mas ela não é incomum. Esses cabos são improvisados geralmente de espetos de churrasco ou confeccionados pelo próprio polvejador a partir de um pedaço de madeira. Não houve nenhum outro relato envolvendo a conexão vegetal durante as entrevistas, da mesma maneira que nenhuma outra prática envolvendo vegetais foi observada durante a pesca.

Dentre as cinco conexões básicas que o ser humano

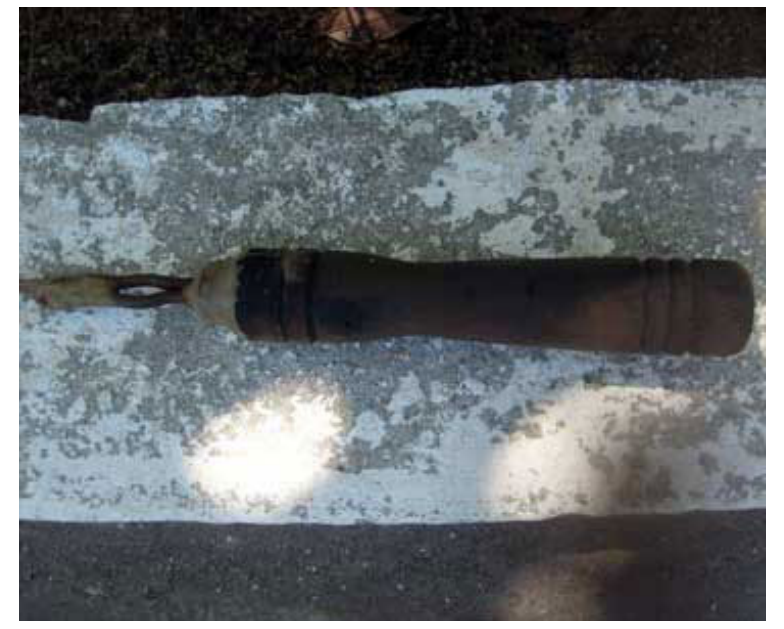

Figura 3. Bicheiro com cabo de madeira utilizado na pesca de polvos em Coroa Vermelha, Santa Cruz Cabrália, Bahia. mantém com o ambiente segundo a proposição de Marques (1995), a conexão com os vegetais foi a que se apresentou mais fraca na pesca local de polvo. As conexões fracas estão previstas por Marques (com. pess.); segundo o autor, se desfeitas, essas conexões comprometem pouco ou não comprometem os traços culturais típicos da atividade, podendo ser substituídos sem que a cultura sofra grande impacto.

\section{Conexão Ser Humano/Animal}

Técnica de captura. Os polvejadores reconhecem dois tipos de polvos, o polvo-comum e o polvo-de-leste, sendo o primeiro mais comumente explotado. Exemplares coletados de polvo-comum foram identificados como pertencentes à espécie Octopus insularis Leite \& Haimovici, 2008, mas não se pode descartar a hipótese de ocorrência de Octopus vulgaris (Cuvier, 1797) na região de estudo (Martins et al. 2011).

A pesca deste animal é realizada de duas maneiras: "por cima do arrecife" ou "por cima das pedras" e "de mergulho" (pesca subaquática). Ambas as estratégias de captura foram também encontradas por Jambeiro (2002), na Vila de Garapuá (Bahia), e por Leite (2007), no Arquipélago de Fernando de Noronha. Em Coroa Vermelha, o polvejamento mais comum ocorre com o deslocamento do pescador sobre o recife a procura do recurso.

A outra técnica de captura é praticada através de mergulho (apneia), na qual o pescador geralmente está equipado com máscara de mergulho e nadadeiras. Nesta modalidade, segundo entrevistados, a pesca é realizada em profundidades de até $5 \mathrm{~m}$. A pesca "de mergulho" é considerada arriscada, pois segundo os pescadores, o polvo capturado pode inserir seus braços nos ouvidos e nariz do pescador, na tentativa de se defender. Em contrapartida, os polvejadores argumentam que os animais capturados por meio da pesca subaquática possuem tamanho e peso superiores quando comparados àqueles capturados sobre o recife, o que torna esta técnica mais rentável. No Arquipélago de Fernando de Noronha, Leite et al. (2008a) afirmam que a maior parte dos polvos adultos são encontrados em uma profundidade mínima de $2 \mathrm{~m}$, o que também pode explicar a obtenção de indivíduos maiores através da pesca subaquática em Coroa Vermelha.

Outra vantagem da pesca de mergulho é que se trata de uma atividade de caráter mais generalista, uma vez que através dela, o pescador pode adquirir outros produtos além do polvo (peixes e lagosta, por exemplo), tendo em vista que esses animais partilham do mesmo habitat: "Quando a maré clareia, eu vou de mergulho. Vai matando um polvo, vai matando um peixinho...". Cabe considerar que a pesca de mergulho também pode ser realizada com arpões, sem o objetivo específico de capturar polvos, sendo esta, uma consequência eventual da atividade, conforme relata um polvejador. 
"[...] a pessoa que vá fazer um mergulho, ai ele já pode achar uma lagosta, já pode matar um peixe e já pode achar até o próprio polvo, aí no caso ele tá indo de mergulho, ele já tá indo com a finalidade de pescar o que ele achar, ele tira um polvo, tira uma lagosta se achar um peixe já mata."

O primeiro passo para realizar a captura de polvos consiste na localização do animal: "Você acha ele já na casa. Você não tem sua moradia? Ele também tem a moradia dele. Tem que buscar ele em casa, porque ele tá dentro de casa, né?" Na pesca subaquática esse procedimento é considerado mais fácil, pois o polvo é facilmente visualizado: "[...] é mais fácil tirar de mergulho. De mergulho, você que nunca à vez não conhece, se você colocar uma máscara, pé de pato, ele é mais visível pra você ver." No polvejamento por cima do recife, esse não é um procedimento simples e exige experiência: "[...] aqui em cima da pedra ele é mais invisível, né?" Todos os pescadores entrevistados afirmaram identificar a loca do polvo a partir de restos de presas (siris, guaiás, conchas e/ ou buzos) deixados em volta do abrigo do animal.

"A casa dele é assim, onde tem muitos marisco, siri, onde tem conchinha, por exemplo, porque ele começa a comer de lá, você tem que ir no giro daquela comida que ele deixou."

Uma vez localizado o animal, os restos de alimento são removidos do entorno. Em seguida, o primeiro bicheiro é inserido no interior da loca com a função de fisgar o animal, quando então o segundo é empregado para auxiliar a remoção. O procedimento exige força e habilidade dos polvejadores: "Pra tirar ele é que tem que ter o jeito."

Os pescadores fazem referência também à captura do polvo: "quando ele tá mariscando". Os polvejadores localizam o animal "andando" sobre o recife e conseguem capturá-lo com as mãos, sem a necessidade do emprego de nenhuma ferramenta. Esse evento é fortuito, ocorrendo raramente.

"[...] quando você tá andando, aí você acontece de pegar alguns deles andando, mariscando de mão, vivinho, né, sem usar o bichêro, né? Aí ele tá andando atrás do siri aí cê pega ele de mão, garra ele de mão e joga ele no saco, a única maneira que tem. É difícil mais acontece."

Muitos polvejadores relataram durante a entrevista a utilização de um instrumento denominado "alavanca" que seria empregado na pesca de polvo em Porto Seguro. Segundo eles, essa ferramenta é utilizada para quebrar o recife quando a captura do polvo através do bicheiro é complicada. A utilização desse instrumento é considerada prejudicial por todos os entrevistados que a ela se referiram.
Segundo os mesmos, a ferramenta promove danos aos recifes, além de dificultar a ocupação destes por outros polvos. Mesmo tendo sido relatado, de acordo com os entrevistados, não se emprega a pesca de alavanca em Coroa Vermelha. De fato, durante as observações diretas não foi presenciada nenhuma prática que se assemelhasse à pesca com alavanca.

Leite et al. (2008b) registraram a pesca de polvo com a utilização de substâncias químicas (como cloro, por exemplo). A pesca realizada com o uso de substâncias químicas além de afetar diretamente o recurso explotado, pode atingir outros organismos presentes no sistema, prejudicando-os. Não foi observado esse tipo de comportamento em Coroa Vermelha e em nenhum momento ele foi abordado pelos polvejadores. Segundo os entrevistados, as únicas formas de capturar polvos são através da utilização do bicheiro, ou esporadicamente, com as mãos, quando o animal é encontrado fora da loca.

Em Coroa Vermelha, a técnica de polvejamento predominante é aquela que ocorre sobre o platô recifal. O fenômeno das marés é um fator preponderante para a realização desta atividade, uma vez que esta só pode ser realizada durante o período no qual os recifes permanecem expostos. Desta forma, raramente ocorre pesca de polvo sobre o platô fora deste período.

"Maré grande seca bem, descobre bastante os arrecife, né? Essa é a maré melhor. Maré morta aí também se pesca, mas a produção é bem menos, Bom mesmo é na maré grande que a maré grande seca bastante, esses lugar descobre tudo."

A manipulação da cadeia trófica (Marques 1991) pode também facilitar a captura de outro recurso importante para a subsistência da comunidade local. Eventualmente, o polvo pode ser utilizado para capturar lagostas. Os pescadores fazem isso com base no conhecimento de que "a lagosta tem medo do polvo". Para tanto, eles amarram o polvo em uma vara com a qual tocam cavidades dos recifes onde possam estar abrigadas as lagostas. De acordo com os polvejadores, ao ver o polvo, as lagostas saem das tocas e, nesse momento, o pescador aproveita para capturá-las.

"Pega lagosta também com o polvo, a gente marra o polvo na ponta duma vara e a gente sai por debaixo da loca da peda, futucando. No lugar que tem a lagosta, que ela vê o polvo, ela não guenta, ela dispara. Nenhuma fica lá dento na loca da peda, ela sai tudo lá debaixo, com medo do polvo. Ela tem muito medo do polvo, ela não quer nem saber [...]"

Essa conexão reflete o conhecimento que os polvejadores possuem a respeito da ecologia trófica dos polvos. Ocorre também neste caso, um acoplamento cognitivo-comportamental, no qual o conhecimento sobre 
a alimentação destes animais condiciona o comportamento de utilizar um recurso (polvo) pra obter outro (lagosta). Os polvejadores que se utilizam desta técnica para capturar lagostas têm que ter um cuidado adicional com os caramurus (Muraenidae), que podem estar à espreita, próximos às lagostas, aguardando a aproximação dos polvos para se alimentarem.

“[...] aonde tem lagosta no fundo, ali perto sempre tem uma moreia. Então digamos assim, é uma espécie de parceria que eles têm, não dá pra entender direito, mas eu vou explicar melhor como é que é a situação: digamos assim se o polvo for comer a lagosta, o polvo vai ser comido pela moreia. A moreia já tá esperando, geralmente ali uma loca onde tem bastante lagosta ali, sempre pode olhar direitinho ali porque ali por perto tem uma moreia, se vier algum polvo por ali, ela pega também."

Segundo a tipologia conexiva (Andrade et al. 2006), a pesca de lagosta utilizando polvos se encaixaria no tipo trófico indireto, já que um recurso alimentar está sendo empregado na captura de outro, e também no tipo econômico indireto, uma vez que as lagostas capturadas podem ser comercializadas.

Esta estratégia de captura de lagostas já foi mais frequente na comunidade, segundo os próprios polvejadores. Ao longo do tempo, esta prática tem se tornado cada vez mais rara e com provável tendência a desaparecer, uma vez que só foi citada pelos polvejadores com mais idade e experiência na pesca. Na classificação de Marques (com. pess.), essa seria provavelmente uma conexão evanescente, se considerada a sua tendência à extinção. A diminuição deste tipo de pescaria se deve, de acordo com os entrevistados, à diminuição nos estoques de lagostas.

Etnoconservação. Segundo Souto (2006), são poucos os trabalhos etnoecológicos que enfocam claramente a conexão entre o conhecimento ecológico local, a conservação e o manejo. O motivo disto, ainda de acordo com ele (Souto 2006), pode ser o fato da etnoconservação consistir em uma forma de abordagem relativamente recente ou mesmo, no caso da pesca, por ser metodologicamente bastante difícil, tendo em vista a necessidade de se lidar com dados de esforço de pesca, levantamento de produção pesqueira, resiliência do ecossistema em questão e até mesmo com capacidade de suporte. Diante disto, no presente artigo serão enfocados apenas alguns aspectos decorrentes da pesca dos polvos que podem estar associados à conservação.

O decréscimo da quantidade de polvos ao longo do tempo foi percebido por todos os polvejadores entrevistados. O aumento da população local, aliado ao crescimento do turismo não apenas na comunidade de Coroa Vermelha, mas também em toda a Costa do Descobrimento, segundo os pescadores, tem sido os fatores responsáveis pela diminuição dos estoques de polvo na localidade.

"Tem diferença [na quantidade], tem diferença porque é muito consumidor. Naquele tempo era bem pouca gente, o polvo num tinha essa saída que hoje tem. Hoje tem barraca de praia, tem restorante, posada, hotel tudo assume o polvo, né, consome o polvo. E esse tempo não, esse tempo era mais os nativo..."

Diante da diminuição gradativa do recurso, parte dos polvejadores acredita que a pesca deva ser ordenada para que o recurso não desapareça. Souto (2004) registrou o mesmo desejo entre pescadores da comunidade de Acupe, com relação a recursos que se tornaram escassos. Em Coroa Vermelha, muitos polvejadores afirmam que gostariam que houvesse um período de proibição de pesca mediante pagamento de seguro desemprego aos polvejadores, visando garantir a manutenção dos estoques locais de polvos.

"Se tivesse a proibição do polvo, eu gostaria também. Porque pelo menos a gente tinha um tempo dele ser recuperado, e não tem proibição pra ele, devia ter porque aí a gente pelo menos recebia o tempo dele pra ele ter tempo de se recuperar."

Outra parte dos entrevistados acredita que o recurso não será extirpado porque pedras (recifes) que nunca emergem fornecem os polvos para os sítios de coleta. Diante desse tipo de afirmação, poderia se esperar que os polvejadores realizassem a pesca sem nenhum critério de seleção, já que a abundância dos polvos estaria associada a recifes que não são explorados. No entanto, outros fatores podem mitigar o comportamento de captura não seletiva de polvos. Um desses fatores é a preferência pela captura de animais grandes, principalmente devido ao maior retorno financeiro. A maior parte dos pescadores entrevistados afirma não capturar indivíduos jovens, ou por causa da pequena rentabilidade ou para permitir que esses animais cresçam e se reproduzam. Argumentos semelhantes a esses foram encontrados por Martins \& Souto (2006), Souto \& Marques (2006) e Souto (2007), respectivamente entre marisqueiras, pescadores de siri e caranguejeiros no Recôncavo Baiano. Outro motivo para a captura de indivíduos de maior porte é a preferência dos consumidores. Muitas vezes os indivíduos jovens são recusados pelo comprador.

"É mais difícil de vender o polvo pequeninho, né? O pessoal reclama muito, o polvinho pequeno 'ah, muito pequeno, eu não vou comprar..."

Apesar de haver uma nítida preferência por animais grandes, alguns entrevistados afirmam coletar indivíduos 
pequenos quando os maiores não são encontrados. Com a recusa do consumidor, os indivíduos muito jovens são muitas vezes destinados ao consumo da família.

Os polvos atingem a primeira maturação sexual com um peso relativamente baixo. Por se tratarem de animais semeoparidores, ou seja, que apresentam apenas um evento reprodutivo ao longo do seu ciclo de vida, a recomendação de um tamanho mínimo para captura é útil, segundo Leite et al. (2008a, p. 87), para "permitir a realização do potencial de crescimento". De acordo com Jambeiro (2002), os tamanhos mínimos para captura vêm sendo estipulados para garantir a manutenção das espécies de polvos. Para a conservação dos estoques de Octopus insularis no Arquipélago de Fernando de Noronha, Leite et al. (2008b.) recomendaram a captura de indivíduos de tamanho superior ao da maturação sexual, com a finalidade de aumentar as chances de cópula e sucesso reprodutivo da espécie.

O tamanho e o peso da primeira maturação sexual em polvos estão fortemente associados a fatores abióticos, principalmente temperatura da água, podendo divergir bastante de região para região (Jambeiro 2002; Silva et al. 2002; Mateazzi 2006). Jambeiro (2002) concluiu que a maturidade sexual de $O$. vulgaris ocorre com cerca de $320 \mathrm{~g}$ em machos e cerca de $710 \mathrm{~g}$ em fêmeas nos recifes de Garapuá, Arquipélago de Tinharé, Bahia. Fernandez-Rueda \& Garcia-Florez (2007) recomendaram para a mesma espécie um peso mínimo de $1000 \mathrm{~g}$ na captura comercial das Asturias (Espanha), enquanto na Grécia, a legislação não permite a captura de $O$. vulgaris com peso inferior a $500 \mathrm{~g}$ (Katsanevakis \& Verriopoulos 2005).

Apesar da maior parte dos entrevistados ter afirmado selecionar indivíduos maiores para captura, há que se considerar que parte dos polvejadores coleta animais de pequeno porte, como pôde ser verificado durante as observações diretas. Não se pode precisar a intensidade do impacto dessa prática sobre os estoques locais, mas é possível que a captura de jovens traga prejuízos à população dos polvos, principalmente pela possibilidade de interrupção precoce do ciclo de vida desses animais sem que estes tenham alcançado a idade reprodutiva. Se essa prática for intensificada, os estoques do recurso podem vir a ser comprometidos, agravando a situação socioeconômica já precária daqueles que dependem diretamente do polvejamento para viabilizar a sobrevivência da sua família.

No que se refere ao petrecho utilizado para a obtenção do recurso, o bicheiro é um instrumento considerado altamente seletivo e de baixo impacto no ambiente por capturar apenas o animal pretendido (Jambeiro 2002; Leite 2007). Segundo Leite et al. (2008b), a pesca com este instrumento permite também a seleção do tamanho do espécime a ser capturado, devido à facilidade de identificação dos indivíduos maiores antes da captura.

Em estimativa preliminar, Jambeiro (2002) comprovou, através de estudo de produção e esforço de pesca, que a pesca de polvos na Vila de Garapuá, realizada apenas de forma artesanal e utilizando o bicheiro, provavelmente permite que a população remanescente deste cefalópode seja responsável pelo repovoamento do recife. A ausência de dados desta natureza relativos à pesca de Coroa Vermelha não permite que se possa afirmar o quanto do estoque é capturado, em média, pelos polvejadores.

De acordo com os entrevistados, há sítios de pesca onde os polvos são mais abundantes. Esses locais são denominados pelos pescadores como os locais mais "maninhos". A abundância do recurso nessas localidades está associada, segundo os polvejadores, à menor exploração a qual estas áreas estão sujeitas, principalmente por conta da dificuldade de acesso.

"Tem lugar que dá mais, tem lugar que dá menos, conforme a peda seje assim, vamo supor, é a gente fica três, dois ou três meses sem ninguém ir nos arrecife, acontece que tem muito polvo, ele dá muito polvo. Mas se toda maré, a gente passear naquela peda, aqui..."

Os locais menos visitados pelos pescadores são aqueles mais afastados da costa, principalmente Recife de Fora e Coroa Alta, devido à dificuldade de transporte (embarcação) para esses sítios. Desta forma, as pedras mais batidas, ou seja, os locais onde o polvejamento acontece de forma mais intensa, são aqueles mais acessíveis, principalmente os recifes de Coroa Vermelha e Mutá. O recife da Ponta Grande é um intermediário em termos de exploração, por estar mais distante da comunidade (ca. $7 \mathrm{~km}$ ) e, por outro lado, possuir acesso terrestre.

Os recifes locais são considerados de propriedade comunal e, em tese, qualquer pessoa de dentro ou de fora da comunidade pode deles usufruir, segundo os polvejadores. O regime de propriedade comunal difere do de livre acesso porque o primeiro apresenta algumas medidas socioculturais que podem atuar como mitigadores das consequências desastrosas da "tragédia dos comuns" abordada por Hardin (1968).

A competência cultural (Souto 2006) é um exemplo de fator que restringe o número de polvejadores que exercem a atividade e consequentemente diminui a pressão sobre o recurso. Apenas as pessoas que desenvolveram um corpo de conhecimento que torna possível a realização da atividade são capazes de executá-la, o que impede que qualquer pessoa possa capturar esse recurso.

No caso dos sítios de pesca mais afastados do distrito de Coroa Vermelha, um atenuante da pressão sobre o recurso pode ser o acesso nos quais o fluxo de pessoas é regulado pelas embarcações que possam efetuar esse deslocamento. Somente os poucos pescadores que possuem barco, ou têm acesso a estes por meio de amigos e parentes, podem chegar aos sítios mais afastados. A dificuldade de acesso, entretanto, não se aplica aos recifes costeiros.

A periodicidade da pesca predominante em Coroa 
Vermelha (sobre o platô recifal) devido ao fenômeno das marés também pode ser um fator importante na conservação do recurso. A pesca por cima do recife é realizada cerca de dez dias por mês, apesar de não terem sido citados dias em que não se pode polvejar na localidade, exceto sob más condições de tempo.

"[...] pode pescar todo dia. O pessoal vai na hora que der, né, na hora que a maré tiver dando. Oferiado é a maré, né? Quando a maré morre, aí raramente vai alguém."

Esporadicamente, os polvejadores abandonam temporariamente a pesca para desenvolver tarefas relacionadas ao turismo quando essas são consideradas mais rentáveis. Os períodos em que diminui a intensidade do polvejamento, ou praticamente não há pesca, podem funcionar como um "descanso" que atenua a pressão sobre o recurso. Alguns pescadores evitam trabalhar aos domingos, mas devido à importância da atividade para a subsistência das famílias, nem sempre é possível se afastar dela em períodos de maré apropriada ao polvejamento.

Segundo Smith \& Wishnie (2000), a conservação em sociedades de pequena escala, caracterizadas essencialmente por possuir algumas centenas a poucos milhares de habitantes e autonomia política, envolve atos ou ações que previnem ou mitigam três problemas: depleção de recursos, degradação de habitat e extirpação de espécies. É provável que a periodicidade da pesca de polvo e a necessidade da competência cultural para a realização da atividade atuem como mitigadores da depleção de recursos e da extirpação da espécie. A coleta de indivíduos jovens por sua vez é um fator que pode influenciar negativamente neste aspecto.

Conforme citado anteriormente, a pesca com bicheiros é altamente seletiva e não possibilita a captura de fauna acompanhante. Além disso, durante a observação direta foi verificado que as tocas de onde o recurso é retirado são preservadas pelos polvejadores, inclusive porque eles acreditam que outros polvos podem vir a ocupá-las.

$\mathrm{O}$ pisoteio de corais vivos parece uma consequência deletéria inerente ao polvejamento sobre os recifes. Verificou-se, no entanto, que os pescadores parecem evitar o pisoteio de corais, principalmente porque o tipo mais abundante, conhecido localmente como baba-de-boi (pertencentes ao gênero Palythoa), secreta uma substância que lhes confere um caráter escorregadio e com isso, aparentemente o prejuízo a estes organismos é minimizado.

Leite et al. (2008a, p. 86), recomendaram algumas medidas para normatização da pesca de Octopus insularis no Arquipélago de Fernando de Noronha com a função de "garantir a conservação do polvo e os ambiente em que habita, compatibilizando-a com uma pesca de pequena escala, principalmente com fins recreativos". Dentre essas medidas, o controle de acesso e o tamanho mínimo para captura, em primeira análise, parecem adequadas à normatização da pesca em Coroa Vermelha, que no momento não possui qualquer tipo de ordenamento. A pesca em áreas de maior profundidade, sugerida por Leite et al. (2008b) entretanto, provavelmente seria de difícil implementação, já que a maioria dos polvejadores locais parecem não dominar a técnica de mergulho.

\section{Conexão Ser Humano / Ser Humano}

Comercialização. A maior parte dos polvejadores entrevistados realiza a pesca para a venda e eventual consumo. Os próprios pescadores são os responsáveis pela comercialização do polvo, que é feita principalmente para barracas de praia e pousadas da região, ou ainda para supermercados em Porto Seguro.

"Eu vendo direto pra os restorante, barracas de praia, cabanas, igualmente a gente aqui tem, né cheio de cabanas... Casas moradas, etc, né. Eu que sou pescador, pego boto na bicicleta e saio por aí, casas de morada, donos de supermercado..."

Inicialmente, pensava-se não haver atravessadores interferindo no processo de comercialização do produto por serem os próprios pescadores os responsáveis pela venda. Posteriormente, verificou-se que alguns dos próprios polvejadores compravam a produção de outros para realizar a revenda. Este processo de intermediação é tido como satisfatório pelos pescadores, mas não é o tipo predominante de comercialização de polvos na comunidade. O mais comum é que o pescador realize a venda do recurso que ele próprio capturou diretamente às barracas de praia, hotéis, pousadas, etc.

Segundo Souto (2004), a intermediação do pescado em comunidades ao longo da costa brasileira, embora apareça com diferentes graus de hierarquia, formas de organização e atuação, é bastante semelhante na estratégia de pagar preços baixos aos produtores e progressivamente mais altos a cada nível hierárquico da cadeia de comercialização. O comércio de polvos em Coroa Vermelha destoa um pouco dessa regra por serem os produtores, na maioria das vezes, os próprios vendedores. Esse fato confere certa vantagem aos polvejadores que não perdem dinheiro ao longo da cadeia produtiva e não dependem de atravessadores para realizar a venda do produto.

O verão é considerado o melhor período de venda, pois nesta época, o produto é mais valorizado e mais fácil de ser comercializado. O preço do quilo de polvo varia de 8 a 10 reais no período de baixa temporada e chega a custar 20 reais na alta temporada.

"Na temporada você tem melhor preço pra vender, porque paga melhor os restorantes, né? E tudo, né? E na baixa temporada é mais barato. É ruim pra vender." 
"[...] o que custa hoje, vamo botar um quilo, quinze reais, vinte reais aí na baixa vem pra dez reais o quilo, né? Oito reais o quilo."

Territorialidade. Na pesca de polvo realizada em Coroa Vermelha, aparentemente não existe posse de locais de pesca. De acordo com informações dos entrevistados, é permitido a qualquer pessoa polvejar nos recifes, inclusive àquelas oriundas de outras localidades, sem que isso gere maiores conflitos. Apesar dessas afirmações terem sido feitas pela totalidade dos entrevistados, muitos deles relataram situações conflitivas com relação à pesca no Parque Municipal Marinho do Recife de Fora. Segundo polvejadores, durante o processo de criação do Parque, área protegida de maior restrição de uso da legislação brasileira, os pescadores foram impedidos de realizar qualquer tipo de atividade pesqueira na localidade. Insatisfeitos com a situação, pescadores se mobilizaram e reividicaram o direito de pescar na área à Secretaria de Meio Ambiente da prefeitura de Porto Seguro. O problema parece ter sido em parte superado com a criação da carteira de polvejador, fornecida pela Secretaria a pescadores cadastrados e que lhes permite a prática da atividade na localidade.

Outro caso de conflito de território no Parque acontece entre funcionários de escunas que conduzem turistas à área e polvejadores que trabalham neste mesmo local. Os funcionários das escunas inserem bandeiras nos recifes com a função de conduzir os turistas sobre o recife e aparentemente também com intenção de restringir o espaço de atuação do polvejador. Os funcionários chegam a abordar pescadores e instruí-los a não se aproximar da área onde se encontram os turistas. Ainda assim, os polvejadores afirmam não ceder às recomendações, mas apesar disso, o conflito aparentemente não gera maiores consequências.

Os demais sítios de coleta de polvo são de uso comum e as restrições de acesso ao recurso estão relacionadas à fatores sócioculturais, tais como respeito, segredo de pesca e competência cultural para o exercício da atividade. Não parece haver nenhuma restrição de acesso aos recursos por pessoas de fora da comunidade. Segundo Hardin (1968), recursos que estão ao alcance de todos tendem a desaparecer, o que ficou conhecido como "tragédia dos comuns". Duras críticas e grandes polêmicas foram geradas em torno desta teoria, entre as quais o fato do autor ter ignorado o papel de regras socioculturais instituídas pelas próprias comunidades que fazem uso dos recursos que acabariam por regular o acesso a estes (e.g., Diegues 2001; Fenny et al. 2001).

Durante as entrevistas, os polvejadores afirmaram existir pesca lado a lado, sem que necessariamente haja uma distância mínima entre eles. Esse comportamento, de acordo com os entrevistados, não gera desavença entre os pescadores.
"[...] vai prevalecer a sorte de cada um. Porque pode acontecer o seguinte: eu tá passando aqui e digamos eu ir aqui, ele ir aqui e o polvo tá do lado, ou no meu ou no lado dele. Porque geralmente quando a gente tá polvejando e tem alguma pedrinha mais alta é sempre sinônimo de algum polvo ali por perto. Aí prevalece a inteligência de cada um."

$\mathrm{O}$ direito de retirada do recurso pertence àquele que o encontrou: "Aqui todo muito pode mariscar na mesma pedra. Por exemplo, se tiver uma pessoa tirando polvo aqui e eu encontrar outro aqui encostadinho, não tem problema nenhum, eu posso tirar. Porque quem achou aqui foi eu." O sucesso na pescaria é considerado pela maioria como sorte e até mesmo merecimento divino.

“[...] aí é a sorte que Deus lhe der, né? Às vez cê tá passando por aqui e eu tô passando aqui vizinho aqui do lado, aí você acha um polvo aqui e eu vou por ali e não tô achando, entendeu? Aí cê vai pelo meio da pedra aqui em linha reta aqui, lá na frente cê vai e acha outro eu não tô lá eu não acho nenhum. É sorte, né? Um dia cê pega mais do que eu, outro dia eu pego mais que você, cê não pega nada... É questão de sabedoria e sorte, né? Merecimento de Deus..."

Durante as observações diretas foi verificado que realmente os polvejadores podem chegar a se aproximar uns dos outros. Contudo, também foi observado que ao chegar ao platô recifal, os polvejadores buscam descrever trajetórias diferentes, chegando até mesmo a evitar a porção do recife onde se encontravam outros colegas. Este comportamento pode ser atribuído a uma regra social de respeito e/ou uma estratégia para otimização da captura. No primeiro caso, a presença de um polvejador inibe a aproximação do outro, principalmente para evitar conflito; no segundo, o pescador evita locais ocupados porque estes provavelmente não apresentam mais o recurso.

De uma maneira ou de outra, tal comportamento sugere que os polvejadores utilizam territórios lineares variáveis descritos durante o seu deslocamento. Seja qual for a motivação, esse território é respeitado pelos demais, que, na prática, evitam aproximação.

" [...] Cada um, cada um. Caiu na pedra cada um toma seu rumo. Um vai pra aqui, outro vai pra ali, um passa por aqui outro passa por cá e tal. Cada um que tiver sorte..."

"[...] a gente subiu na pedra aqui, aí não é só eu né? Sobe mais dois, mais três ou mais quatro. Aí um vai lá pra ponta, outro vai pelo meio da pedra, outro vai pra outra ponta, é assim, entendeu? Espalha. E ninguém pode proibir, ninguém pode falar nada..." 
A proteção do recurso por segredo, também considerada como uma medida territorialista (Souto 2004), foi encontrada no discurso de alguns polvejadores. Uma parte dos entrevistados admite que ao polvejar em um local onde o recurso é abundante, não compartilha a informação com outros pescadores. Muitos alegam que só comunicam o fato a parentes e amigos próximos.

"Eu por sinal eu não tenho esse negócio de usura, né? Eu posso contar assim quando a pessoa bem íntima da gente aqui, amigo, né, é mais amizade. Mas se for uma pessoa que morar lá em Porto Seguro outro pescador ou morar em Cabrália eu não conto, entendeu?"

É importante considerar a dificuldade de se manter o segredo de pesca no polvejamento, sobretudo quando este é realizado nos recifes costeiros. Quando a pesca é realizada nestes locais o polvejador é visto por outros durante a chegada e saída do platô recifal. A estratégia de manutenção de segredo provavelmente funcione melhor quando a pesca acontece em locais mais afastados, onde o acesso ocorre por meio de embarcações. O transporte de polvos em sacos plásticos ao invés de em "enfieiras" conforme relatado anteriormente, também pode ter função de manutenção de segredo.

Recursos protegidos por segredo podem estar sujeitos a uma pressão menor, tendo em vista que estando o recurso concentrado em determinado espaço, não pode ser explotado exaustivamente por outras pessoas. De acordo com Souto (2004, p. 220), "trata-se de uma forma de evitar a presença de competidores e garantir um maior rendimento na explotação". A proteção por segredo tem o potencial de atuar como mitigadora da sobre-explotação pesqueira por reduzir o esforço de pesca devido à quantidade restrita de pescadores usufruindo dos recursos e, consequentemente, gerar implicações conservacionistas positivas (Souto 2004).

\section{Conexão Ser Humano / Sobrenatural}

Poucos são os estudos que tratam da influência do componente sobrenatural na pesca tradicional, detacandose os trabalhos de Marques (1995) e Souto (2004). Os polvejadores entrevistados se referem a Yemanjá ou a sereia como a protetora e/ou dona do mar. Esse componente sobrenatural parece estar bastante presente no imaginário dos polvejadores, mas não foi encontrada nenhuma relação ou influência direta de Yemanjá na pesca de polvo. A crença nesta figura é compartilhada por índios, não-índios e evangélicos.

A figura de Deus está relacionada à abundância e escassez de polvos de acordo com os pescadores. Ele seria o responsável pela regulação dos recursos e de acordo com a Sua vontade, eles estariam abundantes ou escassos. Agradecimentos à figura divina são bastante comuns na pesca, particularmente nos momentos de início e fim da atividade, qualquer que tenha sido o resultado do esforço. A relação com o sobrenatural na pesca de polvo aparentemente não possui nenhum aspecto regulador que possa influir no processo de conservação do recurso local.

\section{Conclusões}

- No que se refere à pesca de polvo, a conexão ser humano vegetal é a mais fraca dentre as cinco conexões básicas propostas por Marques (1995);

- A captura de polvos jovens praticada por parte dos entrevistados pode interferir negativamente na conservação dos estoques do recurso, ao passo que a periodicidade da pesca e a necessidade de competência cultural para a realização da atividade podem atuar positivamente na manutenção dos estoques;

- A comercialização dos polvos é feita predominantemente pelo próprio pescador que capturou o recurso diretamente às barracas de praia, pousadas, hotéis e restaurantes locais, que são os principais compradores do produto;

- A proposta etnoecológica abrangente é aplicável também ao ecossistema recife de coral.

\section{REFERÊNCIAS}

Amaral, A.C.Z. \& Jablonsky, S. 2005. Conservação da biodiversidade marinha e costeira no Brasil. Megadiversidade 1: 43-51.

Andrade, C.T.; Marques, J.G.W. \& Zappi, D. 2006. Utilização de cactáceas por sertanejos baianos: tipos conexivos para definir categorias utilitárias. Sitientibus série Ciências Biológicas 6: 3-12.

Castro, C.B. 1997. Avaliação e Ações Prioritárias para a Conservação da Biodiversidade da Zona Costeira e Marinha - recifes de coral. Disponível em http://www.bdt.fat.org.br/ workshop/costa/recifes/; acesso em mar. 2008.

Diegues, A. C. 2001. Ecologia Humana e Planejamento Costeiro. NUPAUB-USP, São Paulo.

Feeny, D.; Berkes, F.; McCay, B.J. \& Achenson, J.M. 2001. A tragédia dos comuns: vinte e dois anos depois. In: A.C. Diegues \& A.C.C. Moreira (orgs), Espaços Naturais de Uso Comum. NUPAUB-USP, São Paulo, p.17-42.

Fernandez-Rueda, P. \& Garcia-Flórez, L. 2007. Octopus vulgaris (Mollusca: Cephalopoda) fishery management assessment in Asturias (north-west Spain). Fisheries Research 83: 351-354.

Gomes, A.S.; Villaça, R. \& Pezzella, C.A. 2001. Atol das Rocas: ecossistema único no Atlântico Sul. Ciência Hoje 29: 32-39.

Hardin, G. 1968. The tragedy of the commons. Science 162: 1243-1248.

Jambeiro, A.F. 2002. Biologia Quantitativa da população de Octopus vulgaris Cuvier, 1797 no ecossistema recifal de Guarapuá, Cairu - Bahia. Monografia de graduação. 
Universidade Federal da Bahia.

Katsanevakis, S. \& Verriopoulos, G. 2005. Seasonal population dynamics of Octopus vulgaris in the Eastern Mediterranean. Journal of Marine Science 63: 151-160.

Kikuchi, R.K.P.; Leão, Z.M.A.N.; Oliveira, M.D.M.; Dutra, L.X.C. \& Cruz, I.C. 2003. Branqueamento de corais nos recifes da Bahia associado aos efeitos do El Niño 2003. In: Anais do IX Congresso da Associação Brasileira de Estudos do Quaternário, Recife, p. 213.

Leite, T.S. 2007. Taxonomia, Distribuição, Ecologia Alimentare Opções de Manejo de uma Nova Espécie de Polvo (Octopus insularis: Cephalopoda) no Arquipélago de Fernando de Noronha, Brasil. Tese de doutorado. Fundação Universidade do Rio Grande.

Leite, T.S.; Haimovici, M. \& Lins, J.E. 2008a. Uma proposta de manejo para a pesca de polvo (Mollusca: Cephalopoda) na Área de Proteção Ambiental do Arquipélago de Fernando de Noronha, Brasil. Arquivos de Ciências do Mar 41: 81-89.

Leite, T.S.; Haimovici, M. \& Lins, J.E. 2008b. A pesca de polvos no Arquipélago de Fernando de Noronha, Brasil. Boletim do Instituto de Pesca de São Paulo 34: 271-280.

Marques, J.G.W. 1991. Aspectos Ecológicos na Etnoictiologia dos Pescadores do Complexo Estuarino-Lagunar MundaúManguaba, Alagoas. Tese de doutorado. Universidade Estadual de Campinas.

Marques, J.G.W. 1995. Pescando Pescadores: etnoecologia abrangente no Baixo São Francisco. São Paulo, NUPAUBUSP.

Marques, J.G.W. 2001. Pescando Pescadores: ciência e etnociência em uma perspectiva ecológica. São Paulo, NUPAUB-USP.

Martins, V.S. 2008. Uma Abordagem Etnoecológica Abrangente da Pesca de Polvos (Octopus spp.) na Comunidade de Coroa Vermelha (Santa Cruz Cabrália, Bahia). Dissertação de Mestrado. Universidade Estadual de Santa Cruz.

Martins, V.S. \& Souto, F.J.B. 2006. Uma análise biométrica de bivalves coletados por marisqueiras no manguezal de Acupe, Santo Amaro, Bahia: uma abordagem etnoconservacionista. Sitientibus série Ciências Biológicas 6: 98-105.

Martins, V.S.; Schiavetti, A. \& Souto, F.J.B. 2011. Ethnoecological knowledge of the artisan fishermen of octopi (Octopus spp.) in the community of Coroa Vermelha (Santa Cruz Cabrália, Bahia). Anais da Academia Brasileira de Ciências 83(2): 1-10.

Mateazzi, L. 2006. Cultivo de Polvo Comum Octopus vulgaris (CUVIER, 1797). Monografia de Graduação. Universidade de Taubaté.

Montenegro, S.C.S. 2002. A Conexão Homem/Camarão (Macrobrachium carcinus $e$ M. acanthurus) no Baixo Sul Alagoano: uma abordagem etnoecológica. Tese de
Doutorado. Universidade Federal de São Carlos.

Mourão, J.S. 2002. Classificação e Ecologia de Peixes Estuarinos por Pescadores do Estuário do Rio Mamanguape - PB. Tese de doutorado. Universidade Federal de São Carlos.

Mourão, J.S. \& Nordi, N. 2006. Pescadores, peixes, espaço e tempo: uma abordagem etnoecológica. Interciencia 31(5): 358363.

Nishida, A.K. 2000. Catadores de Molusco do Litoral Paraibano: estratégias de subsistência e formas de percepção da natureza. Tese de doutorado. Universidade Federal de São Carlos.

Silva, L.S.; Sobrino, I. \& Ramos, R. 2002. Reproductive biology of the common octopus, Octopus vulgaris Cuvier,1797 (Cephalopoda: Octopodidae) in the Gulf of Cádiz (SW Spain). Bulletin of Marine Science 71(2): 837-850.

Silvano, R.A.M. 2001. Etnoecologia e História Natural de Peixes no Atlântico (Ilha de Búzios, Brasil) e Pacífico (Moreton Bay, Austrália). Tese de doutorado. Universidade Estadual de Campinas.

Smith, E.A. \& Wishnie, M. 2000. Conservation and subsistence in small-scale societies. Annual Review of Anthropology 29: 493-520.

Souto, F.J.B. 2004. A Ciência que Veio da Lama: uma abordagem etnoecológica abrangente das relações ser humano/manguezal na comunidade pesqueira de Acupe, Santo Amaro, Bahia. Tese de doutorado. Universidade Federal de São Carlos.

Souto, F.J.B. 2006. Sociobiodiversidade na pesca artesanal no litoral sul da Bahia. In: R.R. Kubo, J.B. Bassi, G.A. Souza, P.M. Medeiros \& U.P. Albuquerque. Atualidades em Etnobiologia e Etnoecologia. Vol. 3. NUPEEA, Recife, p. 259-274.

Souto, F.J.B. 2007. Uma abordagem etnoecológica da pesca do caranguejo, Ucides cordatus, Linnaeus, 1763 (Decapoda: Brachyura), no manguezal do distrito de Acupe (Santo AmaroBA). Biotemas 20(1): 69-80.

Souto, F.J.B. \& Marques, J.G.W. 2006. "O siri labuta muito!" Uma abordagem etnoecológica abrangente da pesca de um conjunto de crustáceos no manguezal de Acupe, Santo Amaro, Bahia, Brasil. Sitientibus série Ciências Biológicas 6: 106119.

Thé, A.P.G. 2003. Conhecimento Ecológico, Regras de Uso e Manejo Local dos Recursos Naturais na Pesca do Alto-Médio São Francisco, MG. Tese de doutorado. Universidade Federal de São Carlos.

Tomás, A.R.G. 2003. Dinâmica de População e Avaliação do Estoque do Polvo Comum, Octopus cf. vulgaris Cuvier, 1797 (Mollusca, Cephalopoda, Octopodidae) do Sudeste-Sul do Brasil. Tese de doutorado. Universidade Estadual Paulista Júlio de Mesquita Filho. 